\title{
Is a differentiated care model needed for patients with TB? A cohort analysis of risk factors contributing to unfavourable outcomes among TB patients in two states in South India
}

Reynold Washington ${ }^{1,2,3}$, Rajaram Subramanian Potty ${ }^{1 *}$ (D) A. Rajesham ${ }^{4}$, T. Seenappa ${ }^{5}$, Anil Singarajipura ${ }^{5}$, Reuben Swamickan6, Amar Shah6, K. H. Prakash', Arin Karr, Karthikeyan Kumaraswamy', B. S. Prarthana', Bala Krishna Maryala', J. Sushma', Ramesh Dasari', Bharath Shetty', Vikas Panibatla, H. L. Mohan ${ }^{1}$ and Marissa Becker ${ }^{2}$

\begin{abstract}
Background: TB is a preventable and treatable disease. Yet, successful treatment outcomes at desired levels are elusive in many national TB programs, including India. We aim to identify risk factors for unfavourable outcomes to TB treatment, in order to subsequently design a care model that would improve treatment outcomes among these at-risk patients.

Methods: We conducted a cohort analysis among TB patients who had been recently initiated on treatment. The study was part of the internal program evaluation of a USAID-THALI project, implemented in select towns/cities of Karnataka and Telangana, south India. Community Health Workers (CHWs) under the project, used a pre-designed tool to assess TB patients for potential risks of an unfavourable outcome. CHWs followed up this cohort of patients until treatment outcomes were declared. We extracted treatment outcomes from patient's follow-up data and from the Nikshay portal. The specific cohort of patients included in our study were those whose risk was assessed during July and September, 2018, subsequent to conceptualisation, tool finalisation and CHW training. We used bivariate and multivariate logistic regression to assess each of the individual and combined risks against unfavourable outcomes; death alone, or death, lost to follow up and treatment failure, combined as 'unfavourable outcome'.

\footnotetext{
* Correspondence: rajara999@gmail.com

'Karnataka Health Promotion Trust, IT Park, Rajajinagar Industrial Area, Behind KSSIDC Admin. Office, Rajajinagar, Bengaluru, Karnataka 560044, India

Full list of author information is available at the end of the article
}

C C The Author(s). 2020 Open Access This article is licensed under a Creative Commons Attribution 4.0 International License, which permits use, sharing, adaptation, distribution and reproduction in any medium or format, as long as you give appropriate credit to the original author(s) and the source, provide a link to the Creative Commons licence, and indicate if changes were made. The images or other third party material in this article are included in the article's Creative Commons licence, unless indicated otherwise in a credit line to the material. If material is not included in the article's Creative Commons licence and your intended use is not permitted by statutory regulation or exceeds the permitted use, you will need to obtain permission directly from the copyright holder. To view a copy of this licence, visit http://creativecommons.org/licenses/by/4.0/ The Creative Commons Public Domain Dedication waiver (http://creativecommons.org/publicdomain/zero/1.0/) applies to the data made available in this article, unless otherwise stated in a credit line to the data. 


\begin{abstract}
(Continued from previous page)
Results: A significantly higher likelihood of death and experiencing unfavourable outcome was observed for individuals having more than one risk (AOR: 4.19; 95\% Cl: 2.47-7.11 for death; AOR 2.21; 95\% Cl: 1.56-3.12 for unfavourable outcome) or only one risk (AOR: 3.28; $95 \%$ Cl: $2.11-5.10$ for death; AOR 1.71; 95\% Cl: 1.29-2.26 for unfavourable outcome) as compared to TB patients with no identified risk. Male, a lower education status, an initial weight below the national median weight, co-existing HIV, previous history of treatment, drug-resistant $\mathrm{TB}$, and regular alcohol use had significantly higher odds of death and unfavourable outcome, while age $>60$ was only associated with higher odds of death.
\end{abstract}

Conclusion: A rapid risk assessment at treatment initiation can identify factors that are associated with unfavourable outcomes. TB programs could intensify care and support to these patients, in order to optimise treatment outcomes among TB patients.

Keywords: Tuberculosis, Risk-factors, Differentiated care, Unfavourable outcomes, India

\section{Background}

India contributes $27 \%$ of the global burden of Tuberculosis and 24\% of Drug Resistant TB (DR-TB) and almost every third TB death globally is from India [1]. The Government of India plans to 'End TB' through implementation of its National Strategic Plan (NSP) - India 20172025. Ambitious targets for successful treatment outcomes by 2025 have been set: 92\% for Drug Sensitive(DS-TB) and 75\% for DR-TB [2]. In 2017, successful treatment outcomes in India were only $79 \%$ for patients with DS-TB and 46\% for those with DR-TB [3].

In India, the Revised National Tuberculosis Control Program (RNTCP) now referred to as the National TB Elimination Program (NTEP) provides free TB diagnostic and treatment services [3]. In 2012, the Government of India launched the Nikshay platform (Nik- means End, Shay means TB), a web-enabled application to facilitate monitoring of TB patients across India. All private and public health establishments were mandated to notify all TB patients who received a diagnosis or were initiated on treatment into the Nikshay. In 2018, the NTEP rolled out Poshan Abhiyan, a direct benefit cashtransfer of ₹500 per month to patients who are on treatment, in order to supplement their nutrition needs. An unsuccessful/unfavourable TB treatment outcome included the following outcomes: death, loss to follow up and treatment failure. According to the 2019 India TB report, the proportion of TB patients with an unfavourable treatment outcome was $9.3 \%$ in India, and in the southern Indian states of Telangana and Karnataka was 8.6 and $13.9 \%$, respectively. Death was reported for $4.0 \%$ of all TB patients initiated on treatment in India, and $4.0 \%$ in Telangana and $6.2 \%$ in Karnataka [4].

In general, TB programs focus on treatment adherence in order to improve treatment outcomes. Many studies have examined factors impeding treatment adherence. The lack of adequate food, poor communication between healthcare providers and patients, beliefs in traditional healing systems, non-availability of TB services in nearby health facilities, side-effects and pill burden of the drugs, and stigma and discrimination were cited as reasons for poor adherence in qualitative studies that assessed barriers to treatment adherence [5, 6]. Understanding reasons for unfavourable treatment outcomes is critical to optimizing TB treatment programs and improving treatment success rates. There are very few studies that directly link patient level risk factors to unfavourable treatment outcomes. Studies suggest that treatment outcomes could be improved when a package of treatment adherence interventions are offered to patients on TB treatment, such as health education and counselling, digital medication monitoring, material supports to the patient, psychological support to the patient and family and staff education [7].

Worse TB treatment outcomes are often seen more frequently among individuals with co-existing conditions such as diabetes and HIV, heavy alcohol users, smokers, those aged below 25 years and above 50 years, and those who have received previous treatment for TB [8-10]. However, despite this understanding, most TB programs do not identify these individuals with these risk factors as a priority group, nor do they provide any differentiated care to these patients. The NTEP treats all TB patients similarly, with little or no differentiation in the intensity or scope of care and support to patients, with some exceptions for patients co-infected with TB and HIV and those with DR-TB. All TB patients receive routine care by TB health visitors (TBHV), who are supervised by Senior TB treatment Supervisors (STS). The NTEP field staff are minimally trained to assess and identify risks for unfavourable outcomes, or to provide individualised counselling to help the patient cope with, and overcome, treatment adherence challenges.

The United States Agency for International Aid (USAID) funded the Tuberculosis Health Action Learning Initiative (THALI), implemented by Karnataka Health Promotion Trust (KHPT), in partnership with TB Alert India and St John's Medical College and 
Hospital, in three states in south India. THALI is a patient centred, family focused project which aims to enhance TB notification and treatment outcomes among vulnerable urban populations. As a part of THALI, the team designed and implemented a 'Differentiated Care Model (DCM)' to understand whether identifying TB patients with risks of unfavourable outcomes, and subsequently providing more intensive support where required to mitigate those risks, would result in better treatment outcomes. This paper aims to validate the hypothesis that some patients are at a higher risk of experiencing unfavourable treatment outcomes due to the presence of certain risk characteristics. We plan to evaluate the impact of the differentiated care model on improving outcomes among TB patients in a subsequent paper.

\section{Methods}

\section{Study setting}

The USAID/THALI project was initiated in two large cities in southern India: Bengaluru in Karnataka and Hyderabad in Telangana. In the third year of the project, the approach was refined and scaled up to other select towns and cities in Karnataka, Telangana and the neighbouring state of Andhra Pradesh. This paper focuses on analyses of patients only from Karnataka and Telangana. The selected geographies covered a total population of 18.6 million urban people in 15 districts of Karnataka and 8.1 million urban people in 6 districts of Telangana. In total, this covered 69 cities/towns (61 in Karnataka and 8 in Telangana). In these selected cities/town, the project recruited Community Health Workers (CHWs), who were local residents, to conduct outreach activities. The outreach activities included: i) awareness generation on $\mathrm{TB}$; ii) referrals of symptomatic cases; iii) risk and need assessment of patients initiated on TB treatment; iv) treatment follow-ups; v) contact screening and vi) counselling services.

\section{Study tools}

In consultation with the NTEP staff, the project developed two tools for administration to all TB patients initiated on treatment. The first tool was the "Risk and Needs Assessment (RANA)" tool and was used to identify persons with potential risks for unfavourable treatment outcomes (see additional file 1 for details). The second tool was the "Prevention Care and Support Card (PCS)" and was used to register patients for follow-up visits and record data on assessments and provision of care and support activities, test results and actions taken during each follow-up visit, until the treatment outcome was declared (see additional file 2 for details).

The CHWs were trained on how to administer the tools through both classroom and field sessions. Cluster Coordinators $(\mathrm{CC})$, recruited in a ratio of $1 \mathrm{CC}: 5$ CHWs, provided on-the-job supportive supervision to the CHWs. The team pre-tested the RANA tool for 2 weeks in Bengaluru and Hyderabad, and adapted it for simplicity and uniformity in assessment, recording and interpretation of the data, before it was widely used across the project.

\section{Study procedure}

First, we obtained a list of all the persons diagnosed with $\mathrm{TB}$ in the project geographies from the respective NTEP staff (see Fig. 1). Subsequently, the CHWs administered the RANA tool and registered patients who consented for follow-up visits using the PCS. We could include only those $\mathrm{TB}$ patients who were resident within the towns/cities within the project geographies. The RANA

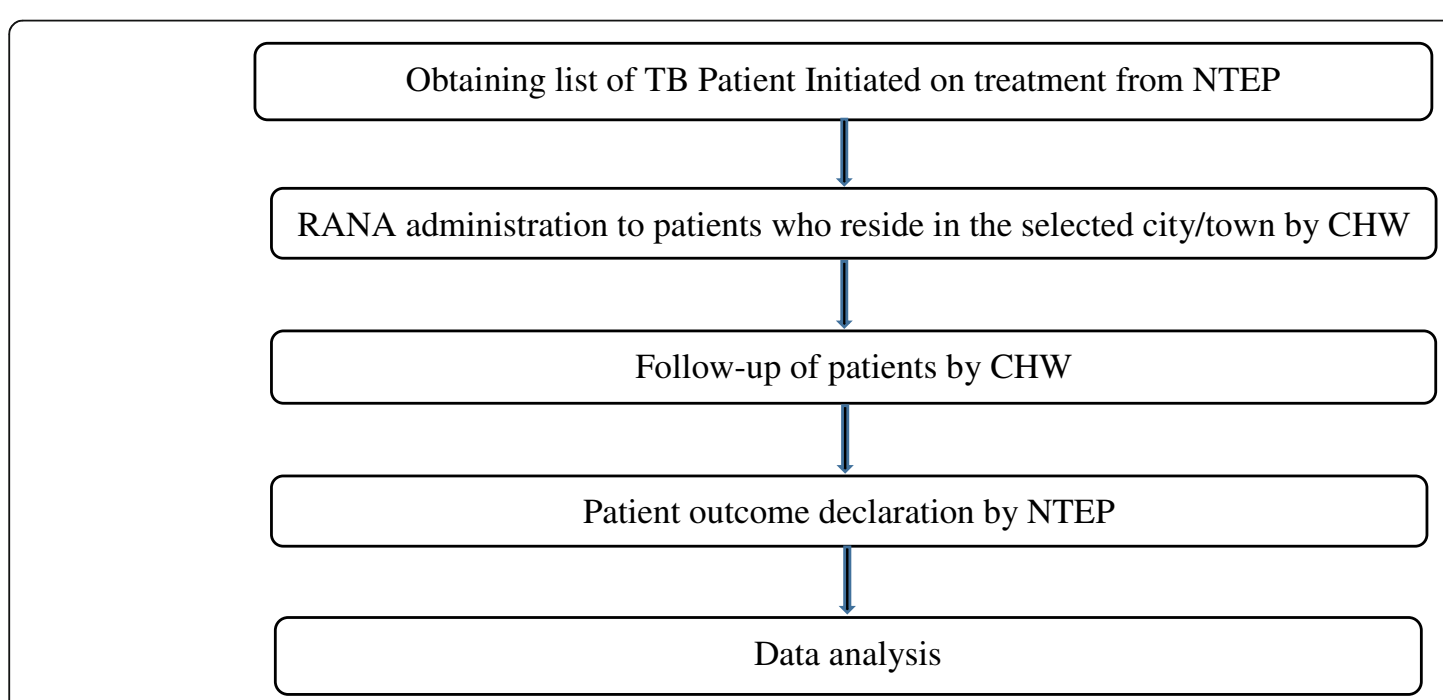

Fig. 1 Study procedures followed 
tool was administered to the patient, however in rare instances when the patient was unable to provide the information him/herself, due to significant illness, information was collected from the primary caregiver in the family.

The RANA tool assessed the patient and/or family member's understanding of $\mathrm{TB}$ and its treatment, explored family level support for the patient, listed social, nutritional and livelihood needs, identified factors that were presumed to be a risk for an unfavourable outcome to TB treatment and noted the type of follow-up preferred (in-person or other) by the patient. Each interview took approximately $25-40 \mathrm{~min}$, and was conducted in a venue convenient to the patient, such as the home or the place of treatment. Initially, paper-based entries were entered onto a Management Information System, however during the course of project implementation this process changed to combine data collection and entry using a mobile application. RANA tool implementation took place in Bengaluru and Hyderabad from June, 2018.

\section{NTEP operational definitions}

Treatment outcomes as defined by the NTEP are listed below: [11].

Cured: An individual with microbiologically confirmed $\mathrm{TB}$ at the beginning of the treatment who was smear or culture-negative at the end of complete treatment.

Treatment success: An individual with TB who was either cured or completed treatment.

Died: An individual with TB who was known to have died from any cause whatsoever while on treatment.

Failure: An individual with TB whose biological specimen is positive by smear or culture at the end of the treatment.

Lost to follow-up: An individual with TB whose treatment was interrupted for one consecutive month or more.

Not evaluated: An individual with TB for whom no treatment outcome is assigned (formerly "transfer out").

Treatment regimen changed: An individual with TB who underwent a change in treatment regimen (formerly referred to as "switched over to MDR treatment").

Unfavourable TB treatment outcomes include: Death, Failure and Lost to follow up.

\section{Data analysis}

We combined three different data sets in order to perform our analysis. For risk identification we used data from the RANA tool. For outcome data, we used the THALI PCS tool as well as the official NTEP data from the Nikshay. The data-sets were linked using the Nikshay identity number and patient's contact number. At the beginning of August 2019, we extracted data on patients who were 18 years or older at the time of $\mathrm{TB}$ diagnosis and notification, and whose RANA had been carried out in the months of July, August and September 2018. These patients had been initiated on TB treatment, 0-8 months prior to the administration of RANA, with a mean of about 2 months. We restricted the analysis to this cohort of patients in order to ensure that we had treatment outcomes for the majority of the patients. The treatment outcomes were extracted from the PCS card on July 31,2019 , or earlier. In the event that the treatment outcome data was not available in the PCS dataset, we extracted treatment outcome from the Nikshay data. In our analysis, we only included patients from Karnataka and Telangana who had data on treatment outcome declared by the month of July 2019, and who also had both a completed RANA and PCS card.

We defined two outcome indicators for the analysis: i) Death and ii) Unfavourable outcome which included death, failure or Lost to Follow Up (LFU).

Based on empirical knowledge and available evidence, we considered the following factors as potential risks for unfavourable outcomes: i) age above 60 years; ii) living alone; iii) HIV, iv) diabetes; v) undernutrition; vi) previous treatment for TB; vii) drug-resistant $\mathrm{TB}$ and viii) history of regular (daily) consumption of alcohol. Information on risk factors listed above were recorded based on patient's history and/or documented laboratory reports (HIV, diabetes) as applicable.

We were unable to use BMI as our indicator of malnutrition as anthropometric measurements were not feasible within the field conditions. Hence, we used weight at the time of treatment initiation as our measure and categorised it based on whether it was below, or equal to and greater, than the median weight of TB patients as recorded in the National Guideline on Nutrition and TB (43 kg for males and $38 \mathrm{~kg}$ for females) [12]. We considered patients to be undernourished if their weight at the time of treatment initiation was below these values.

Data was analysed using Stata version 14. We examined socio-economic and demographic characteristics. We conducted bivariate analysis to understand whether the presence of any of the above considered risk factors were associated with the two outcome indicators. Subsequently, we applied multivariate logistic regression to determine the independent effect of each of the individual risk factors, as well as combined risk factors on the two outcomes. Thus, we considered two multivariate logistic regression models. In the first multivariate logistic regression model, we considered risk characterisation based on all the stated risks, as well as the other background characteristics of the patient. In the second model, we considered the individual risk factors along with the other background characteristics of the patient. We considered two different multivariable regression models because we wanted to understand how the 
individual risk factors independently influenced the outcome variables and how these risks factors as a whole influenced the outcome variables. This analysis will inform which individual characteristics that would need to be considered in the Differentiated Care Model.

\section{Ethical approval}

The Institutional Ethics Committee of St John's Medical College and Hospital provided the ethics approval for program data review and analysis. The State TB office and local NTEP officials in the two states provided regulatory approval for access to Nikshay data and to interview patients and conduct follow-up visits.

\section{Results}

\section{Socio-demographic characteristics and risk factors}

Overall, data was available for $4749 \mathrm{~TB}$ patients resident in the THALI project geographies within the states of Karnataka and Telangana. THALI PCS provided treatment outcome data for 4075 patients and Nikshay data was used to obtain outcomes for the remaining 674 patients. The patient's background and risk factors are shown in Table 1 . Nearly two-thirds of the patients were from Karnataka, females constituted $38 \%$ of the patient population and only $21 \%$ had completed 10 th grade, $23 \%$ of patients with an initial weight measurement had a value below the median value reported for the all India level according to sex of the person $(43 \mathrm{~kg}$ for males and $37 \mathrm{~kg}$ for females) and $60 \%$ had a weight that was equal to or above the median value. The initial weight was either not measured or not documented for $17 \%$ of the patients.

Approximately $12 \%$ of patients were aged 60 or above, $4 \%$ lived alone, $2 \%$ were reported to be HIV positive, $5 \%$ reported to have diabetes, $16 \%$ were previously treated for TB, 3\% had DR-TB, and 13\% reported consuming alcohol regularly. Overall, $30 \%$ of patients were identified to have only one of these stated risks, and $11 \%$ had more than one risk.

\section{Treatment outcomes}

Treatment outcome data is shown in Table 2. In total, about 3\% of patients died and $6 \%$ experienced an unfavourable outcome. A higher proportion of patients in Karnataka had an unfavourable outcome (8\%). Undernourished patients experienced higher death rates and unfavourable outcome ( 4 and $10 \%$ ), as compared to patients with initial weight equal to the national level median or higher (2 and $5 \%$ ).

The proportion who died or had an unfavourable outcome were higher among patients with more than one of the stated risks (6 and 12\% respectively) as compared to those without any of the stated risks (1\% death and $4 \%$ unfavourable outcome). Similarly, patients having only one of the stated risks also had experienced higher deaths $(5 \%)$ and unfavourable outcomes $(8 \%)$ than those without any risk.

Table 3 shows the results using logistic regression to determine the odds ratios and adjusted odds ratios of the patient experiencing death, or unfavourable outcome as defined earlier, according to background characteristics and any risk. Patient with more than one of the stated risk factors had a significantly higher likelihood of dying and/or experiencing an unfavourable outcome as compared to patients without any of the risk factors (AOR: 4.19; 95\%CI: $2.47-7.11$ for death; AOR: 2.21 ; 95\% CI: $1.56-3.12$ for unfavourable outcome). Undernutrition and education status below matriculation (10th grade) of the patient were also seen to significantly result in death and/or unfavourable outcome. TB patients with initial weight below the median weight were 2.1 times (95\%CI: $1.38-3.14)$ and 2.0 times (95\%CI: $1.50-2.61$ ) more likely to die or experience unfavourable outcome respectively, as compared to patients with initial weight equal to the median or higher. Patients from Karnataka also had a significantly higher likelihood of an unfavourable outcome as compared to patients from Telangana (AOR: 2.35 ; 95\%CI: 1.71-3.23) as did males as compared to females (AOR: 1.63; 95\% CI: 1.20-2.21).

Results from the second logistic regression that considered the stated risk factors individually are given in Table 4. Out of the stated risk factors considered, four factors including patients who are aged 60 and above (AOR: 2.15; 95\%CI: 1.37-3.37), who consume alcohol regularly (AOR: 2.09 ; 95\%CI: $1.35-3.25$ ), who were previously treated for TB (AOR: 1.65; 95\%CI: 1.08-2.51), and those who were living with HIV (AOR: 4.75 ; 95\%CI: 2.29-9.86) were significantly more likely to experience death, as compared to patients without these risks. Age of the patient was not a significant risk factor for an unfavourable outcome, though it was for death. Additionally, patients with DR-TB were significantly more likely to experience an unfavourable outcome as compared to patients without DR-TB (AOR: 2.33; 95\%CI: 1.41-3.87). Those patients with undernutrition were found to have a significantly higher likelihood of death (AOR: 1.98; 95\%CI: 1.30-3.00) and/or unfavourable outcome (AOR: 1.89; 95\%CI: 1.43-2.50).

When we considered all the stated risk factors individually into the model, patients from Karnataka experienced significantly higher likelihood of death (AOR: 1.55; 95\%CI: 1.01-2.35) as well as unfavourable outcome (AOR: 2.46; 95\%CI: 1.79-3.39) as compared to patients from Telangana. Educational status above 10th standard was found protective against both death as well as unfavourable outcome in comparison with those with lesser education. The odds of males experiencing an unfavourable outcome was 1.7 times (95\%CI: 1.24-2.30) higher than females. 
Table 1 Demographic characteristics and risk factors among TB patients

\begin{tabular}{|c|c|c|}
\hline Characteristics & Percent & Numbe \\
\hline \multicolumn{3}{|l|}{ Name of the State } \\
\hline Karnataka & 66.4 & 3153 \\
\hline Telangana & 33.6 & 1596 \\
\hline \multicolumn{3}{|l|}{ Sex } \\
\hline Female & 37.8 & 1797 \\
\hline Male & 62.2 & 2952 \\
\hline \multicolumn{3}{|l|}{ Initial weight ${ }^{\mathrm{a}}$} \\
\hline Below median value & 22.8 & 1081 \\
\hline Median value or above & 60 & 2850 \\
\hline Unknown & 17.2 & 818 \\
\hline \multicolumn{3}{|l|}{ Religion } \\
\hline Hindu & 70.0 & 3326 \\
\hline Muslim & 26.3 & 1249 \\
\hline Others & 3.7 & 174 \\
\hline \multicolumn{3}{|l|}{ Education status } \\
\hline$<5$ Standard & 44.8 & 2126 \\
\hline 5-10 Standard & 33.9 & 1612 \\
\hline Above 10 Standard & 21.3 & 1011 \\
\hline \multicolumn{3}{|l|}{ Marital Status } \\
\hline Single & 22.0 & 1046 \\
\hline Married & 72.5 & 3443 \\
\hline Marriage dissolved & 5.1 & 240 \\
\hline Not known & 0.4 & 20 \\
\hline \multicolumn{3}{|l|}{ Type of TB } \\
\hline Extra Pulmonary TB & 24.4 & 1158 \\
\hline Pulmonary TB & 75.6 & 3591 \\
\hline \multicolumn{3}{|l|}{ Age } \\
\hline Below 60 & 88.0 & 4178 \\
\hline 60 and above & 12.0 & 571 \\
\hline \multicolumn{3}{|l|}{ Previously treated for TB } \\
\hline No & 84.0 & 3989 \\
\hline Yes & 16.0 & 760 \\
\hline \multicolumn{3}{|l|}{ DR TB } \\
\hline No & 97.1 & 4611 \\
\hline Yes & 2.9 & 138 \\
\hline \multicolumn{3}{|l|}{ Drink alcohol } \\
\hline No & 87.1 & 4135 \\
\hline Yes & 12.9 & 614 \\
\hline \multicolumn{3}{|l|}{ Living alone } \\
\hline No & 96.1 & 4565 \\
\hline Yes & 3.9 & 184 \\
\hline
\end{tabular}

Table 1 Demographic characteristics and risk factors among TB patients (Continued)

\begin{tabular}{lll}
\hline Characteristics & Percent & Number of cases \\
\hline HIV & 98.2 & 4662 \\
$\quad$ Negative & 1.8 & 87 \\
$\quad$ Positive & & \\
Diabetes & 95.1 & 4518 \\
No & 4.9 & 231 \\
$\quad$ Yes & & \\
Number of risks present & b \\
No risk & 58.9 & 2797 \\
$\quad$ Only one risk present & 30.0 & 1424 \\
$\quad$ More than one risk present & 11.1 & 528 \\
Total percent & 100 & 4749
\end{tabular}

Note: Included patients aged 18 years and above whose RANA was administered between July and September and also treatment outcome was declared

${ }^{a}$ Considered median value of $43 \mathrm{Kgs}$ for males and of $38 \mathrm{Kgs}$ for females

${ }^{\mathrm{b}}$ Risks include, aged 60 and above, previously treated patients, DR TB patients, using alcohol, living alone, HIV positive patient, Diabetes patient

\section{Discussion}

The identification of patients at high risk of experiencing an unfavourable outcomes is essential in order to ensure that these high-risk patients are provided with a more intensified follow up and this is an essential first step in a "differentiated care model". In our study, we found that those educated less than 10th standard, living with HIV, undernourished, with a history of previous TB treatment, with DR-TB, with regular alcohol use and age $>60$ years were more likely to die as a result of TB. With the exception of age, all of these factors also had a higher likelihood of an unfavourable outcome. Additionally, males and those from Karnataka also has a higher risk of unfavourable outcome. All of these risk categories would therefore qualify for a more intensive model of care and support during TB treatment.

The differentiated care model is a well-known approach for care for people living with HIV (PLHIV). This model has been successfully used to categorise stable versus unstable PLHIV in order to provide differentiated care [13]. In India, PLHIV with TB are: screened regularly using a four symptom screening, a priority group for diagnosis by Cartridge based Nucleic Acid Amplification Test (CB-NAAT), and recommended for early initiation of both anti-tuberculosis treatment (ATT) as well as early initiation of anti-retroviral treatment (ART). Differentiated care is provided by ART centres, which are staffed by a multidisciplinary team of doctors, counsellors, nurses, pharmacists and others. Similarly, for DR-TB, the Government of India has established a wide network of labs across the country to enable early diagnosis and has created nodal treatment centres in almost every district, staffed by doctors, 
Table 2 Treatment Outcomes (death or experienced unfavourable outcomes ${ }^{c}$ ) according to background characteristics and risk factors

\begin{tabular}{llll}
\hline Characteristics & $\begin{array}{l}\text { Experienced } \\
\text { death }\end{array}$ & $\begin{array}{l}\text { Experienced } \\
\text { unfavourable } \\
\text { outcome }\end{array}$ & $\begin{array}{l}\text { Number } \\
\text { of cases }\end{array}$ \\
& &
\end{tabular}

\section{Name of the State}

Karnataka

Telangana

Sex

$$
\text { Female }
$$

Male

Initial weight ${ }^{\mathrm{a}}$

Below median value

Median value or above

Unknown

Religion

Hindu

Muslim

Others

\section{Education status}

$<5$ Standard

5-10 Standard

Above 10 Standard

\section{Marital Status}

Single

Married

Marriage dissolved

Not known

Type of TB

$$
\begin{aligned}
& \text { Extra Pulmonary TB } \\
& \text { Pulmonary TB }
\end{aligned}
$$

Age

$$
\begin{aligned}
& \text { Below } 60 \\
& 60 \text { and above }
\end{aligned}
$$

Previously treated for TB

$$
\text { No }
$$$$
\text { Yes }
$$

DR TB

$$
\text { No }
$$$$
\text { Yes }
$$

Drink alcohol

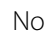

Yes

Living alone 3.1

\section{7}

3.2

10.0

\section{3}

1596

1797

2952

1081

2850

818

3326

1249

174

2126

1612

1011

1046

3443

240

20

\begin{tabular}{|c|c|c|c|}
\hline Characteristics & $\begin{array}{l}\text { Experienced } \\
\text { death }\end{array}$ & $\begin{array}{l}\text { Experienced } \\
\text { unfavourable } \\
\text { outcome }\end{array}$ & $\begin{array}{l}\text { Number } \\
\text { of cases }\end{array}$ \\
\hline \multicolumn{4}{|l|}{ HIV } \\
\hline Negative & 2.6 & 6.0 & 4662 \\
\hline Positive & 11.5 & 16.1 & 87 \\
\hline \multicolumn{4}{|l|}{ Diabetes } \\
\hline No & 2.7 & 6.2 & 4518 \\
\hline Yes & 2.2 & 4.8 & 231 \\
\hline \multicolumn{4}{|l|}{ Number of risk present ${ }^{b}$} \\
\hline No risk & 1.2 & 4.0 & 2797 \\
\hline Only one risk present & 4.5 & 8.4 & 1424 \\
\hline More than one risk present & 6.1 & 11.9 & 528 \\
\hline Total percent & 2.7 & 6.2 & 4749 \\
\hline
\end{tabular}

Table 2 Treatment Outcomes (death or experienced unfavourable outcomes ${ }^{\mathrm{C}}$ ) according to background characteristics and risk factors (Continued)

Note: Included patients aged 18 years and above whose RANA was administered between July and September and also treatment outcome was declared

${ }^{\mathrm{a}}$ Considered median value of $43 \mathrm{Kgs}$ for males and of $38 \mathrm{Kgs}$ for females ${ }^{\mathrm{b}}$ Risk present include, aged 60 and above, previously treated patients, DR TB patients, using alcohol, living alone, HIV positive patient, Diabetes patient 'Unfavourable outcome includes death, failure and LFU patients

laboratory technicians and counsellors. Thus, TB patients with HIV or DR-TB have greater access to more rapid, individualised and more comprehensive care, from multi-skilled teams. We have shown in our study that there are at least 4-5 other categories of patients that also require intensive and personalised care from a team of care providers.

We found that only five of the risk factors that we had initially considered, were significantly increased the likelihood of death and/or unfavourable outcomes. Diabetes and living alone did not turn out to be significantly associated with an increased odds of death or with unfavourable outcome. However, undernutrition was identified as an independent risk factor for death and/or unfavourable outcomes. We intended to use body mass index as the measure for malnutrition. However, measuring weight and height were not always feasible to do in the field. Moreover, for those who did have data available on weight and height, these were often collected at different times during the course of the disease and its treatment. Hence, we chose the single indicator of whether the initial weight that was measured was lower, or equal to and greater than the median, as referred to in the handbook on Nutrition and TB. While this may be a very crude measure, it is fairly simple and straightforward for front line workers to collect and to manage.

A systematic review indicated diabetes to be associated with death and unfavourable outcome among those on TB treatment [14]. This association was not seen in our 
Table 3 Multivariate logistic regression for treatment outcomes (death and unfavourable outcomes) that considered background characteristics and combined risk of DCM

\begin{tabular}{|c|c|c|c|c|c|c|c|c|c|c|}
\hline \multirow[t]{2}{*}{ Characteristics } & \multicolumn{5}{|c|}{ Experienced death } & \multicolumn{5}{|c|}{ Experienced unfavourable outcome ${ }^{c}$} \\
\hline & \multirow[t]{2}{*}{ UOR } & \multirow[t]{2}{*}{$\mathrm{AOR}$} & \multicolumn{2}{|c|}{$95 \% \mathrm{Cl}$} & \multirow[t]{2}{*}{$p$-value } & \multirow[t]{2}{*}{$\mathrm{UOR}$} & \multirow[t]{2}{*}{ AOR } & \multicolumn{2}{|c|}{$95 \% \mathrm{Cl}$} & \multirow[t]{2}{*}{$p$-value } \\
\hline Name of the State & & & & & & & & & & \\
\hline Telangana (Reference) & 1.00 & 1.00 & & & & 1.00 & 1.00 & & & \\
\hline Karnataka & 1.55 & 1.42 & 0.94 & 2.16 & 0.099 & 2.52 & 2.35 & 1.71 & 3.23 & $<0.001$ \\
\hline \multicolumn{11}{|l|}{ Sex } \\
\hline Female (Reference) & 1.00 & 1.00 & & & & 1.00 & 1.00 & & & \\
\hline Male & 1.53 & 0.97 & 0.64 & 1.48 & 0.883 & 2.28 & 1.63 & 1.20 & 2.21 & 0.002 \\
\hline \multicolumn{11}{|l|}{ Initial weight ${ }^{a}$} \\
\hline Median value or above (Reference) & 1.00 & 1.00 & & & & 1.00 & 1.00 & & & \\
\hline Below median value & 2.45 & 2.08 & 1.38 & 3.14 & $<0.001$ & 2.38 & 1.98 & 1.50 & 2.61 & $<0.001$ \\
\hline Weight unknown & 2.05 & 2.12 & 1.32 & 3.38 & 0.002 & 1.64 & 1.74 & 1.25 & 2.43 & 0.001 \\
\hline \multicolumn{11}{|l|}{ Religion } \\
\hline Muslims (Reference) & 1.00 & 1.00 & & & & 1.00 & 1.00 & & & \\
\hline Hindus & 1.09 & 0.97 & 0.64 & 1.48 & 0.888 & 1.26 & 1.09 & 0.81 & 1.46 & 0.573 \\
\hline Others & 1.89 & 1.84 & 0.81 & 4.15 & 0.143 & 1.47 & 1.44 & 0.76 & 2.72 & 0.261 \\
\hline \multicolumn{11}{|l|}{ Education status } \\
\hline Above 10 Standard (Reference) & 1.00 & 1.00 & & & & 1.00 & 1.00 & & & \\
\hline$<5$ Standard & 8.28 & 5.39 & 2.11 & 13.79 & $<0.001$ & 3.59 & 2.68 & 1.67 & 4.31 & $<0.001$ \\
\hline 5-10 Standard & 5.12 & 3.96 & 1.53 & 10.22 & 0.004 & 3.02 & 2.41 & 1.50 & 3.86 & $<0.001$ \\
\hline \multicolumn{11}{|l|}{ Marital Status } \\
\hline Single (Reference) & 1.00 & 1.00 & & & & 1.00 & 1.00 & & & \\
\hline Married & 2.01 & 1.06 & 0.60 & 1.87 & 0.839 & 1.30 & 0.88 & 0.63 & 1.24 & 0.472 \\
\hline Marriage dissolved & 2.51 & 0.93 & 0.38 & 2.26 & 0.872 & 1.64 & 1.07 & 0.59 & 1.94 & 0.815 \\
\hline Not known & $\mathrm{NE}$ & $\mathrm{NE}$ & $\mathrm{NE}$ & $\mathrm{NE}$ & $\mathrm{NE}$ & 2.12 & 2.67 & 0.57 & 12.44 & 0.211 \\
\hline \multicolumn{11}{|l|}{ Type of TB } \\
\hline Extra Pulmonary TB (Reference) & 1.00 & 1.00 & & & & 1.00 & 1.00 & & & \\
\hline Pulmonary TB & 1.68 & 1.00 & 0.99 & 0.60 & 1.632 & 0.98 & 1.31 & 0.92 & 1.86 & 0.138 \\
\hline \multicolumn{11}{|l|}{ Number of risk present ${ }^{b}$} \\
\hline No risk (Reference) & 1.00 & 1.00 & & & & 1.00 & 1.00 & & & \\
\hline Only one risk present & 3.94 & 3.28 & 2.11 & 5.10 & $<0.001$ & 2.21 & 1.71 & 1.29 & 2.26 & $<0.001$ \\
\hline More than one risk present & 5.40 & 4.19 & 2.47 & 7.11 & $<0.001$ & 3.28 & 2.21 & 1.56 & 3.12 & $<0.001$ \\
\hline
\end{tabular}

Note: Included patients aged 18 years and above whose RANA was administered between July and September and also treatment outcome was declared. UOR Unadjusted odds ratio. AOR - Adjusted odds ratio. $\mathrm{Cl}$ - Confidence Interval

${ }^{a}$ Considered median value of $43 \mathrm{Kgs}$ for males and of $38 \mathrm{Kgs}$ for females

${ }^{\mathrm{b}}$ Risk include, aged 60 and above, previously treated patients, DR TB patients, using alcohol, living alone, HIV positive patient, Diabetes patient

'Unfavourable outcome includes death, failure and LFU patients

study. This could be due to the fact that diabetes screening among TB patients in our project geographies is not universal and was captured only from available patient reports. The prevalence of diabetes in the general population ranges from 12 to $18 \%$, while in our study, it was less than 5\% among TB patients. Understanding the true prevalence of diabetes among people with TB is important for appropriate management and is recommended within the Ayushman Bharat primary health care program in India [15]. The incidence of peripheral neuropathy in patients with $\mathrm{TB}$ and diabetes tends to be high [16] but this can be managed when identified during intensive follow-up. Hence, identification of diabetes among TB patients and provision of relevant care would be important in a differentiated care model, even though diabetes did not stand out significantly in our analysis.

Age above 60 years was not independently associated with an unfavourable $\mathrm{TB}$ treatment outcome in the multifactorial logistic regression analysis, though it was significantly associated with higher rates of death. The 
Table 4 Multivariate logistic regression for (death and unfavourable outcomes) that considered background characteristics and individual risks of DCM

\begin{tabular}{|c|c|c|c|c|c|c|c|c|c|c|}
\hline \multirow[t]{2}{*}{ Characteristics } & \multicolumn{5}{|c|}{ Experienced death } & \multicolumn{5}{|c|}{ Experienced unfavourable outcome $^{b}$} \\
\hline & $\overline{U O R}$ & $\mathrm{AOR}$ & \multicolumn{2}{|c|}{$95 \% \mathrm{Cl}$} & $\mathrm{p}$-value & UOR & $\mathrm{AOR}$ & \multicolumn{2}{|c|}{$95 \% \mathrm{Cl}$} & $\mathrm{p}$ - value \\
\hline \multicolumn{11}{|l|}{ Name of the State } \\
\hline Telangana (Reference) & 1.00 & 1.00 & & & & 1.00 & 1.00 & & & \\
\hline Karnataka & 1.55 & 1.54 & 1.01 & 2.35 & 0.045 & 2.52 & 2.46 & 1.79 & 3.39 & $<0.001$ \\
\hline \multicolumn{11}{|l|}{ Sex } \\
\hline Female (Reference) & 1.00 & 1.00 & & & & 1.00 & 1.00 & & & \\
\hline Male & 1.53 & 0.95 & 0.61 & 1.48 & 0.825 & 2.28 & 1.69 & 1.24 & 2.30 & 0.001 \\
\hline \multicolumn{11}{|l|}{ Initial weight $^{\mathrm{a}}$} \\
\hline Median value or above (Reference) & 1.00 & 1.00 & & & & 1.00 & 1.00 & & & \\
\hline Below median value & 2.45 & 1.98 & 1.30 & 3.00 & 0.001 & 2.38 & 1.89 & 1.43 & 2.50 & $<0.001$ \\
\hline Weight unknown & 2.05 & 1.96 & 1.22 & 3.15 & 0.005 & 1.64 & 1.70 & 1.22 & 2.37 & 0.002 \\
\hline \multicolumn{11}{|l|}{ Religion } \\
\hline Muslims (Reference) & 1.00 & 1.00 & & & & 1.00 & 1.00 & & & \\
\hline Hindus & 1.09 & 0.94 & 0.62 & 1.45 & 0.788 & 1.26 & 1.10 & 0.82 & 1.47 & 0.544 \\
\hline Others & 1.89 & 1.71 & 0.75 & 3.91 & 0.205 & 1.47 & 1.40 & 0.74 & 2.66 & 0.304 \\
\hline \multicolumn{11}{|l|}{ Education status } \\
\hline Above 10 Standard (Reference) & 1.00 & 1.00 & & & & 1.00 & 1.00 & & & \\
\hline$<5$ Standard & 8.28 & 5.38 & 2.10 & 13.83 & $<0.001$ & 3.59 & 2.74 & 1.71 & 4.41 & $<0.001$ \\
\hline 5-10 Standard & 5.12 & 3.99 & 1.55 & 10.31 & 0.004 & 3.02 & 2.41 & 1.51 & 3.87 & $<0.001$ \\
\hline \multicolumn{11}{|l|}{ Marital Status } \\
\hline Single (Reference) & 1.00 & 1.00 & & & & 1.00 & 1.00 & & & \\
\hline Married & 2.01 & 1.09 & 0.62 & 1.93 & 0.763 & 1.30 & 0.95 & 0.68 & 1.34 & 0.779 \\
\hline Marriage dissolved & 2.51 & 0.88 & 0.35 & 2.23 & 0.795 & 1.64 & 1.22 & 0.66 & 2.24 & 0.523 \\
\hline Not known & $\mathrm{NE}$ & $\mathrm{NE}$ & NE & NE & NE & 2.12 & 3.23 & 0.70 & 14.96 & 0.133 \\
\hline \multicolumn{11}{|l|}{ Type of TB } \\
\hline Extra Pulmonary TB (Reference) & 1.00 & 1.00 & & & & 1.00 & 1.00 & & & \\
\hline Pulmonary TB & 1.68 & 1.09 & 0.66 & 1.80 & 0.737 & 2.06 & 1.37 & 0.96 & 1.95 & 0.081 \\
\hline \multicolumn{11}{|l|}{ Age } \\
\hline Below 60 (Reference) & 1.00 & 1.00 & & & & 1.00 & 1.00 & & & \\
\hline 60 and above & 2.39 & 2.15 & 1.37 & 3.37 & 0.001 & 1.36 & 1.12 & 0.79 & 1.60 & 0.533 \\
\hline \multicolumn{11}{|l|}{ Previously treated for TB } \\
\hline No (Reference) & 1.00 & 1.00 & & & & 1.00 & 1.00 & & & \\
\hline Yes & 2.17 & 1.65 & 1.08 & 2.51 & 0.020 & 1.58 & 1.18 & 2.11 & 0.00 & 0.003 \\
\hline \multicolumn{11}{|l|}{ DR TB } \\
\hline No (Reference) & 1.00 & 1.00 & & & & 1.00 & 1.00 & & & \\
\hline Yes & 2.61 & 1.83 & 0.86 & 3.89 & 0.117 & 3.22 & 2.33 & 1.41 & 3.87 & 0.001 \\
\hline \multicolumn{11}{|l|}{ Drink alcohol } \\
\hline No (Reference) & 1.00 & 1.00 & & & & 1.00 & 1.00 & & & \\
\hline Yes & 2.71 & 2.09 & 1.35 & 3.25 & 0.001 & 2.16 & 1.38 & 1.01 & 1.88 & 0.043 \\
\hline \multicolumn{11}{|l|}{ Living alone } \\
\hline No (Reference) & 1.00 & 1.00 & & & & 1.00 & 1.00 & & & \\
\hline Yes & 0.79 & 0.68 & 0.24 & 1.89 & 0.460 & 0.75 & 0.40 & 1.42 & 0.38 & 0.473 \\
\hline
\end{tabular}


Table 4 Multivariate logistic regression for (death and unfavourable outcomes) that considered background characteristics and individual risks of DCM (Continued)

\begin{tabular}{|c|c|c|c|c|c|c|c|c|c|c|}
\hline \multirow[t]{2}{*}{ Characteristics } & \multicolumn{5}{|c|}{ Experienced death } & \multicolumn{5}{|c|}{ Experienced unfavourable outcome ${ }^{b}$} \\
\hline & $\overline{\mathrm{UOR}}$ & AOR & \multicolumn{2}{|c|}{$95 \% \mathrm{Cl}$} & $\mathrm{p}$-value & $\overline{\mathrm{UOR}}$ & AOR & \multicolumn{2}{|c|}{$95 \% \mathrm{Cl}$} & $p$-value \\
\hline \multicolumn{11}{|l|}{ HIV } \\
\hline Negative (Reference) & 1.00 & 1.00 & & & & 1.00 & 1.00 & & & \\
\hline Positive & 4.96 & 4.75 & 2.29 & 9.86 & $<0.001$ & 3.01 & 2.61 & 1.41 & 4.82 & 0.002 \\
\hline \multicolumn{11}{|l|}{ Diabetes } \\
\hline No (Reference) & 1.00 & 1.00 & & & & 1.00 & 1.00 & & & \\
\hline Yes & 4.96 & 0.74 & 0.29 & 1.86 & 0.521 & 0.75 & 0.70 & 0.37 & 1.32 & 0.266 \\
\hline
\end{tabular}

risk of death is high and therefore these patients require additional supports. Perhaps, TB death in this age is confounded by other co-morbidities. This needs further exploration. We therefore feel that we still need to include age above 60 years within the differentiated care model, because these TB patients may require more intensive care and support, in order to prevent untimely death, whether directly as a result of $\mathrm{TB}$ or because of other underlying disease conditions, which should be adequately screened for and appropriately managed. The risk of unfavourable outcomes appears to be higher in Karnataka, when compared to the neighbouring states. This reasons for this difference needs further exploration.

In many resource limited settings, the provision of follow up comprehensive care for all TB patients is often not feasible, nor necessary. However, identifying and ensuring that all patients with one or more risks associated with experiencing any unfavourable outcome or death alone are followed up intensively and are provided with a differentiated care approach, that addresses their specific treatment-related, social, nutritional, behavioural and psychological needs.

TB patients have diverse disease, demographic and behavioural characteristics. These characteristics are easily obtained through patient history and, in India, are expected to be recorded for TB patients on the Nikshay platform. Therefore, identifying patients with these risk factors is feasible in India, if a risk and needs assessment is carried out and documented into Nikshay in a systematic manner. Data analytics can be directly built into the system to highlight a patient who needs the differentiated care approach. The study has indicated that few of the risks that are important for assessment of whether a TB patient requires more specific and comprehensive care or whether routine care is sufficient. The fields for all these risk factors are configured on the current Nikshay platform, but are rarely given adequate attention.
Some of the limitations of our study include the following. Previous studies have indicated age below 25 years as a risk factor for poor outcomes but our analysis was restricted to those above the age of 18 and the number between 18 and 25 was not large enough to analyse separately. In a few instances, we noted inconsistency between treatment outcomes reported in Nikshay and our data. In these instances, we used our recorded outcome as we were able to validate this directly from the patient or a family member. For $14 \%$ of patients, we depended on Nikshay, as we did not have an outcome recorded in our database. The characteristics of this group of patients for whom we did not have an outcome recorded in the PCS, were not independently analysed to examine whether any differences existed between this group and those for whom we had treatment outcomes recorded in the PCS. Finally, since the RANA administration was carried out on an average of almost 2 months after the initiation of treatment, there could be underestimation of deaths, as about $50 \%$ of TB deaths occur within 2 months of treatment initiation [17]. Our data was also unable to draw inferences on patient's treatment adherence during the follow-up period. However, we note that reports of missed doses among patients that were intensively followed up by CHWs was rare.

\section{Conclusions}

Achieving favourable treatment outcomes for drug sensitive TB to $92 \%$ and DR-TB to $75 \%$ requires innovative approaches. The Differentiated Care Model (DCM), with an initial Risk and Needs Assessment (RANA), appears to be an essential first step innovation, in order to first identify those at greater risk of an unfavourable treatment outcome and then to ensure follow up care and support tailored to their needs. The study provides a model, with process and tools to implement this innovation at scale. 


\section{Supplementary information}

Supplementary information accompanies this paper at https://doi.org/10. 1186/s12889-020-09257-5.

Additional file 1. Tool for risk and needs assessment (RANA).

Additional file 2. Prevention Care and Support Card (PCS).

\section{Abbreviations}

AOR: Adjusted odds ratio; ART: Anti-retroviral treatment; ATT: Antituberculosis treatment; CB-NAAT: Cartridge based nucleic acid amplification test; CC: Cluster coordinators; CHW: Community health workers; Cl: Confidence interval; DCM: Differentiated care model; DOTS: Directly observed treatment short-course; DR-TB: Drug resistant TB; DS-TB: Drug sensitive TB; HIV: Human immunodeficiency virus; LFU: Lost to Follow-up; NSP: National strategic plan; NTEP: National TB Elimination Program; PCS: Prevention care and support card; PLHIV: People living with HIV; RANA: Risk and needs assessment; RNTCP: Revised National Tuberculosis Control Program; STS: senlor TB treatment supervisors; TB: Tuberculosis; TBHV: TB health visitor; THALI: Tuberculosis health action learning initiative; USAID: United States Agency for International Aid

\section{Acknowledgements}

We are grateful to USAID, New Delhi, India for funding this study as a part of the larger project namely, Tuberculosis Health Action Learning Initiative (THALI). We appreciate and acknowledge the hard work put in by the CHW and CC in collecting and recording the data, while simultaneously counselling and caring for the patient. Finally, we acknowledge all the TB patients who spent their time and responded to the questions with patience.

Disclaimer: The U.S. Agency for International Development administers the U.S foreign assistance program providing economic and humanitarian assistance in more than 80 countries worldwide. This presentation is made possible by the generous support of the American people through the United States Agency for International Development (USAID). The contents are the responsibility of the authors and do not necessarily reflect the views of USAID or the United States Government.

\section{Authors' contributions}

RW, PKH, KK, PBS, SJ and MB designed the DCM approach. RW, RSP, KK, PBS, $\mathrm{PKH}, \mathrm{BS}, \mathrm{RD}$, and VP supported the development and finalization of the study tools. RSP, SJ, PBS, BKM, RD and BS trained the field staff. RD, VP, BKM and BS coordinated and supervised the data collection and data entry. VP and HLM administratively supported the project and data collection. RSP did the statistical analysis and interpreted the results. RW and RSP wrote the first draft of the manuscript. MB did the final edit. MB, PBS, SJ, BS, RD, AK, AR, ST, AS, RS, AS, VP and HLM offered comments on the draft and critically revised the manuscript. All authors read and approved the final manuscript.

\section{Funding}

This study is made possible by the generous support of the American People through the United States Agency for International Development (USAID). The work described in this article was implemented under the USAID Tuberculosis Health Action Learning Initiative (THALI) Project, managed by Karnataka Health Promotion Trust under the terms of Cooperative Agreement Number AID-386-A ${ }^{-16}-00005$. Staff of the funding agency critically reviewed the draft and offered comments to improve the paper.

\section{Availability of data and materials}

Some restrictions will apply with sharing the data. Data cannot be shared publicly without the approval form the donor agency and the concerned NTEP office. The de-identified data used for the paper can be obtained from the corresponding author with permission from KHPT, the donor agency and the concerned State TB officer.

\section{Ethics approval and consent to participate}

The State TB office and local NTEP officials in the two states provided regulatory approval for access to Nikshay data and to interview patients and conduct follow-up visits. The Institutional Ethics Committee of St John's Medical College and Hospital provided the ethics approval for program data review and analysis. Oral informed consent was taken from all the participants. The data used for the analysis was collected as a part of the programme, wherein patients verbal consent was obtained for recording the details as well as for follow-up visits.

\section{Consent for publication}

Not applicable.

\section{Competing interests}

The authors have declared that no competing interests exist.

\section{Author details}

${ }^{1}$ Karnataka Health Promotion Trust, IT Park, Rajajinagar Industrial Area, Behind KSSIDC Admin. Office, Rajajinagar, Bengaluru, Karnataka 560044, India. ${ }^{2}$ Department of Community Health Sciences, University of Manitoba, Winnipeg, Manitoba, Canada. ${ }^{3}$ St John's Research Institute, Bengaluru, India. ${ }^{4}$ Office of the Joint Director (TB), Commissionerate of Health and Family Welfare, Hyderabad, Telangana, India. ${ }^{5}$ Office of the Joint Director (TB), Lady Willingdon State TB Centre, Bengaluru, Karnataka, India. ${ }^{6}$ Tuberculosis and Infectious Diseases Division, USAID/India, New Delhi, India. ${ }^{7}$ TB Alert India, Hyderabad, India.

Received: 6 February 2020 Accepted: 14 July 2020

Published online: 24 July 2020

\section{References}

1. World Health Organization. Global tuberculosis report 2018. Geneva: WHO; 2018. Licence: CC BY-NC-SA 3.0 IGO.

2. Ministry of Health with Family Welfare. National Strategic Plan for TB Elimination. New Delhi: MOHFW; 2017. Central TB division, Directorate General of Health Services, Nirman Bhavan.

3. Ministry of Health with Family Welfare. India TB Report 2018 Revised National Control Programme Annual Status Report. New Delhi: MOHFW. Nirman Bhavan: Central TB Division, Directorate General of Health Services; 2017.

4. Ministry of Health with Family Welfare. India TB Report 2019 Revised National Control Programme Annual Status Report. New Delhi: MOHFW 2019. Central TB division, Directorate General of Health Services, Nirman Bhavan.

5. Gugssa Borua C, Shimels T, Bilal Al. Factors contributing to non-adherence with treatment among TB patients in Sodo Woreda, Gurage zone, southern Ethiopia: a qualitative study. J Infect Public Health. 2017;10(5):527-33.

6. Deshmukh RD, Dhande DJ, Sachdeva KS, Sreenivas A, Kumar AM, Satyanarayana S, et al. Patient and provider reported reasons for lost to follow up in MDRTB treatment: a qualitative study from a drug resistant TB Centre in India. PLoS One. 2015:10(8):e0135802.

7. World Health Organization. Guidelines for treatment of drug-susceptible tuberculosis and patient care, 2017 update. Geneva: WHO; 2017. Licence: CC BY-NC-SA 3.0 IGO

8. Ramachandran G, Agibothu Kupparam HK, Vedhachalam C, Thiruvengadam K, Rajagandhi V, Dusthackeer A, et al. Factors influencing tuberculosis treatment outcome in adult patients treated with thrice-weekly regimens in India. Antimicrob Agents Chemother. 2017;61(5):e02464-16.

9. Negin J, Abimbola S, Marais BJ. Tuberculosis among older adults - time to take notice. Int J Infect Dis. 2014;32:135-7.

10. Kigozi G, Heunis C, Chikobvu P, Botha S, van Rensburg D. Factors influencing treatment default among tuberculosis patients in a high burden province of South Africa. Int J Infect Dis. 2017;54:95-102.

11. Chaudhuri AD. Recent Changes in Technical and Operational Guidelines for Tuberculosis Control Programme in India - 2016: A Paradigm Shift in Tuberculosis Control. J Assoc Chest Phys. 2017;5(1):1-9.

12. Ministry of Health with Family Welfare. Guidance Document: Nutritional Care and Support for Patients with TB in India. New Delhi: MOHFW; 2017. Central TB division, Directorate General of Health Services, Nirman Bhavan.

13. Mesic A, Fontaine J, Aye T, Greig J, Thwe TT, Moretó-Planas L, et al. Implications of differentiated care for successful ART scale-up in a concentrated HIV epidemic in Yangon, Myanmar. J Int AIDS Soc. 2017; 20(Suppl 4):21644.

14. Baker MA, Harries AD, Jeon CY, et al. The impact of diabetes on tuberculosis treatment outcomes: a systematic review. BMC Med. 2011:9:81. https://doi. org/10.1186/1741-7015-9-81. 
15. NHSRC. Ayushman Bharat comprehensive primary health care through health and wellness centers operational guidelines. Baba Gangnath Marg, Munirka, Delhi: NIHFW Campus; 2018.

16. Hossain MD, Ahmed JU, Rahim MA, Musa A, Latif ZA. Bangladesh national guidelines on the management of tuberculosis and diabetes mellitus comorbidity (summary). Ind J Endocrinol Metab. 2016;20(6):853-7.

17. Birlie A, Tesfaw G, Dejene T, Woldemichael K. Time to death and associated factors among tuberculosis patients in Dangila Woreda, Northwest Ethiopia. PlosOne. 2015;10(12):e0144244.

\section{Publisher's Note}

Springer Nature remains neutral with regard to jurisdictional claims in published maps and institutional affiliations.

Ready to submit your research? Choose BMC and benefit from:

- fast, convenient online submission

- thorough peer review by experienced researchers in your field

- rapid publication on acceptance

- support for research data, including large and complex data types

- gold Open Access which fosters wider collaboration and increased citations

- maximum visibility for your research: over $100 \mathrm{M}$ website views per year

At BMC, research is always in progress.

Learn more biomedcentral.com/submissions 